\title{
Exploring the risk-taking tendency among migrant workers in the COVID-19 pandemic: The role of ontological security
}

\author{
Qiang Yang, Jiale Huo* and Yue Xi \\ School of Economics and Management, Southwest Jiaotong University, Chengdu, China
}

Received 10 October 2020

Accepted 15 December 2020

\begin{abstract}
. groups most affected by the pandemic. second study. workplace and social bad behavior.

\section{Introduction}

The COVID-19 pandemic in 2020 poses a threat to most of the world's workers, in addition to the negative impact on the economy and health $[1,2]$, the secondary disaster of the pandemic is that it also changes the social and living environment of the people in most countries [3]. For example, people may be asked to maintain social distance for a

\footnotetext{
${ }^{1}$ All authors contributed equally to the paper.

*Address for correspondence: Jiale Huo, School of Economics and Management, Southwest Jiaotong University, No. 111, North 1st Section, 2nd Ring Road, Chengdu, 610031, China. E-mail: yangjournal@163.com.
}

BACKGROUND: The COVID-19 pandemic has changed the social environment of most laborers around the world and has profoundly affected people's ontological security and behavior choices. Among them, the migrant workers are one of the

OBJECTIVE: This study explored the mechanism of the impact of the scarcity of ontological security caused by the pandemic on the risk-taking tendency of migrant workers in China through two studies.

METHODS: This study adopts two experimental method, with 514 participants in the first study and 357 participants in the

RESULTS: The results show that the pandemic-induced scarcity perception of ontological security promotes their risk-taking tendency, and the migrant workers' cognitive reflection ability, sense of unfairness and expected benefits play a significant mediating role in this process. The scarcity perception of ontological security promotes migrant workers' risk-taking tendency by reducing the cognitive reflection ability, triggering the sense of unfairness and overstating expected benefits.

CONCLUSIONS: The conclusion of this study can help migrant workers, enterprises and government to avoid potential

Keywords: Pandemic control, sense of unfairness, scarcity perception, cognitive reflection, expected benefits

longer period of time [4], as a result, discrimination and violence against Asian and minority groups caused by the COVID-19 pandemic also broke out in most countries [5-7]. In China, where the pandemic first broke out, people's living environment has also been greatly affected. Data from a study shows that $90 \%$ of native Chinese showed discrimination and social exclusion against Wuhan residents and other groups in the early stage of the outbreak in China [6], and low-income people and non-local workers face a higher probability of being discrimination [8]. According to statistics, there are more than 288 million migrant workers in China [9]. Most of them leave their rural hometowns in remote areas to 
find jobs in fast-growing cities and pursue better lives [10-12]. Most migrant workers $(60 \%)$ work in the manufacturing industry and produce OEM products for most companies worldwide, including textiles, electronics, toys, automobiles, and shipbuilding [13]. They are the main "source of China's low-cost labor, and have made tremendous contributions to China's rapid development in the past 30 years. However, migrant workers have high mobility, low wages, complicated backgrounds and lack of basic vocational skills, which have also become unstable factors for enterprises and society [14]. Compared with the middle class and the affluent class, migrant workers are more affected when facing disasters or crises [15]. They are facing with higher layoffs, unemployment and survival pressure, and a lower probability of public medical support [16]. Therefore, they are more likely to perceive changes in the social living environment during the pandemic, and fall into a state of the scarcity of ontological security. We believe that the threat to the sense of security posed by such changes in the social environment will affect the behavioral choices of this group, especially their risktaking tendency, and this impact seems to continue for a long time with the development of the pandemic. With the effective control of the first round of pandemics in Asia and Europe, countries have begun to resume work and production, which seems to let people see the possibility of restoration of their living environment and their sense of security. However, with the increase in the movement and gathering of people, large-scale infections after the resumption of work have appeared in many countries. The scarcity perception of migrant workers' sense of security may change accordingly and further affect their risk-taking tendency, which increases the corporate and societal factors of instability. Whether and how the scarcity of ontological security caused by the changes in the social environment posed by the COVID-19 pandemic will change the risk-taking tendency of migrant workers is a concern of this research, at the same time, this is also a key issue that governments and companies want to understand during the pandemic prevention and control period.

Specifically, this study focuses on the impact of the perceived scarcity of ontological security (PSOS) on the risk-taking tendency of Chinese migrant workers during the pandemic period. The concept of ontological security put forward by Giddens is used to measure people's perception of the sustainable stability of the environment and the psychological state of their continuous self-identity [17], which comes from the psychological feelings of individuals in the process of their interaction with the environment. On the one hand, the stable interaction between the individual and the environment creates a sense of trust and stability between people and the environment, that is to say, they believe that their environment is stable, orderly and predictable [18]. On the other hand, the sense of trust and stability formed between the individual and the environment helps people form confidence in the continuity of self-identity, That means, they believe that there is continuity between the past, the present and the future selves, and that they are stable and developing individuals, so they reach the state of ontological security [19]. Different from general sense of security, ontological security starts from continuous environmental interaction rather than single environmental interaction, emphasizing the long-term, stable, orderly and predictable continuous interaction relationship between people and the external environment of daily life, as well as the sense of security established and developed on this relationship [20]. Therefore, we believe that it can better predict the impact of changes in the social environment during the pandemic on individual security. The sense of ontological security is usually integrated into daily life and is not perceived by people. However, when the external environment is threatened by drastic changes, the concept that is not easy to detect will be highlighted [21]. This is because drastic changes in the external environment tend to disrupt people's daily life order and the stable interaction between people and the environment, and destroy the psychological security state formed in the stable environment for a long time. People perceive the scarcity of ontological psychological security and reduce their confidence in the continuity of self-identity [22]. Although ontological security has a good early warning effect on people's behavioral trends in crises [16], existing literature mainly examines how disaster experiences can undermine people's ontological security, such as exploring environmental factors that affect ontological security and the performance of psychological stress after ontological security is threatened [23, 24]. Few studies have paid attention to the influence of the PSOS on the possible behavioral changes of individuals, especially the risk-taking tendency of migrant workers.

In order to contribute to this research, we conducted two studies through different control methods, and verified the impact mechanism of PSOS caused by the COVID-19 pandemic on the risk-taking tendency of migrant workers. In the first study, we 
examined the influence of PSOS on the overall risktaking tendency of migrant workers. In the second study, we subdivided the risk-taking areas of migrant workers to verify the mechanism of this effect in five aspects: Social, Recreational, Financial, Health/ Safety, and Ethical. The theoretical value and innovation of this research are mainly reflected in two aspects. On the one hand, this study regards ontological security as a kind of resource. Based on the theory of resource scarcity, the relationship between the PSOS and risk-taking tendency is derived, which complements the research in related fields and enriches the theory of ontological security. On the other hand, this study explains the internal mechanism of the impact of the PSOS on migrant workers' risktaking tendency. At present, there is limited evidence-based literature about the impact of the COVID19 pandemic on the psychology and behavior of the disadvantaged workers. The conclusion of this study not only provides a new research idea for the study of resource scarcity and disadvantaged people's behavior. It can also help migrant workers to better respond to the changes in the social living environment and carry out self-regulation, help enterprises and the government to timely understand the risk-taking tendency of migrant workers during the pandemic period, reduce the potential bad behaviors in the workplace and public places.

\section{Literature review}

\subsection{Ontological security and scarcity perception}

Ontological security is the basic sense of security and trust of people in society. It refers to the ontology's confidence and demand for the continuity of self-identity and the stability of the surrounding social and physical environment [17]. Sociological studies have found that after a disaster occurs, the sense of security of the body will be periodically changed, interrupted or completely eliminated, which has the ability to hinder residents from recovering and rebuilding their lives from the disaster [22]. People with perceived ontology security scarcity experience anxiety and tend to seek different methods to regain their ontological security, such as seeking a stable residence [25] or reconstructing a regular life order $[22,26]$.

At the individual level, the existing research on the ontological security mainly focuses on the direct impact of natural disasters (such as hurricanes, floods, etc.) on people's psychology, and examines how disaster experiences can destroy the ontological security of affected residents. Such as exploring the environmental change factors that affect the ontological security, and the performance of psychological stress after the ontological security is threatened (Table 1). However, no research has focused on the impact of the PSOS on the risk-taking tendency of vulnerable groups in the context of the COVID-19 pandemic.

Different from traditional natural disasters, the impact of the COVID-19 pandemic on people's social living environment includes not only the threat from disease, but also man-made disasters caused by the prevalence of global nationalism and racism caused by the politicization of the virus. Some studies believe that the sociopolitical impact of a compounded natural and man-made disaster combined with physical and psychological displacement is best subsumed under the concept of ontological security [22]. Therefore, it is worth exploring the impact of the

Table 1

Relevant research on ontology security in disasters

\begin{tabular}{|c|c|c|c|}
\hline Authors & Research topics & Event & Key findings \\
\hline [18] & Mental health & Tasmania's forestry conflicts & $\begin{array}{l}\text { Ontological security speaks to the (human) universal and } \\
\text { deeply emotional: living in and with vulnerability, } \\
\text { precarity, and anxiety. }\end{array}$ \\
\hline [27] & Mental health & $\begin{array}{l}\text { Women's experiences of being } \\
\text { homeless with their children } \\
\text { in Victoria, Australia }\end{array}$ & $\begin{array}{l}\text { Homelessness appeared to have adverse effects on women's } \\
\text { wellbeing, mental health and ontological security. }\end{array}$ \\
\hline [28] & Mental health & $\begin{array}{l}\text { Undocumented immigrant } \\
\text { young adults in Florida }\end{array}$ & $\begin{array}{l}\text { Meaningful social connections result in positive emotional } \\
\text { states and improve young immigrants' ontological security. }\end{array}$ \\
\hline [16] & $\begin{array}{l}\text { Psychological } \\
\text { trauma recovery }\end{array}$ & $\begin{array}{l}\text { The } 2016 \text { magnitude } \\
7.8 \text { Kaikoura earthquake }\end{array}$ & $\begin{array}{l}\text { Disaster preparedness cannot weaken the threat of disaster } \\
\text { to the ontological security of vulnerable groups. }\end{array}$ \\
\hline [29] & Mental health & $\begin{array}{l}\text { The Southern Alberta } \\
\text { Flood of } 2013\end{array}$ & $\begin{array}{l}\text { women and people with stronger emotional and social } \\
\text { ties to their neighbourhoods are most likely to experience } \\
\text { disrupted ontological security. }\end{array}$ \\
\hline [22] & $\begin{array}{l}\text { Psychological } \\
\text { trauma recovery }\end{array}$ & Hurricane Katrina & $\begin{array}{l}\text { Intangible losses have an important psychological effect on } \\
\text { community redevelopment and recovery from trauma. }\end{array}$ \\
\hline
\end{tabular}


COVID-19 pandemic situation on people's behavior choices from the perspective of ontology security.

\subsection{Scarcity mindset theory}

Scarcity mindset theory [30] is a kind of "emerging" theory to explain the social phenomenon and behavior related to scarcity. Scarcity mentality theory proposes that scarcity will lead to scarcity mentality, that is, in the face of resource scarcity, individuals' perception of scarcity will make them focus on the current resource shortage problem, thus ignoring other relevant information [30, 31]. Scarcity mentality changes the individual's thinking mode and decision-making behavior: trade-off thinking is a unique way of thinking caused by scarcity, which mainly refers to the fact that the unmet needs will capture the individual's attention and produce decision-making problems; internal thoughts and proactive interference are the main reasons for this phenomenon The former means that any thinking in the brain will have a profound impact on the individual's overall cognitive ability, while the latter refers to the neglect behavior caused by placing the thinking center when an individual thinks about something [30]. Tunneling is a representative phenomenon caused by scarcity mentality, that is, scarcity causes individuals to focus on an urgent event and ignore other potentially useful information [30]. Norris and Huber Krum proposed that the scarcity state affects individual decisionmaking behavior through the influence of attention, information and consequence assessment, which are closely related to decision-making [32]. Huijsmans and Micheli's neuroimaging research shows that under the scarcity mentality mode, the activity of the orbital prefrontal cortex is increased, that is, the scarcity mentality has an impact on the individual decision-making evaluation [33]; at the same time, the activity of the dorsal prefrontal cortex of the individual under the scarcity mentality mode is reduced, that is, the scarcity mentality has an impact on the goal-oriented choice of individual decision-making, whether in behavioral experimental research or brain imaging research It shows that scarcity mentality has a significant impact on individual risk behavior decision-making. Research has proved that scarcity mentality comes from the feeling of scarcity of different resources, such as money, time, social support and work ability. However, there seems to be no research on scarcity mentality caused by ontological security. Therefore, based on the COVID-19 pandemic, this article explores the impact of migrant workers' PSOS on their risk-taking tendency.

\section{Research hypothesis}

\subsection{PSOS and risk-taking tendency}

Risk-taking tendency is a psychological concept, which mainly refers to the behavior that may lead to positive and negative results [34] which is the situational characteristics, decision-makers, and the tendency to interact between the two [35]. Risktaking tendency refers to the decision-making behavior under the uncertain situation where the expected result and its probability are unknown [36]. Life History Theory believes that individuals in a resource-rich living environment will show a higher degree of psychological security and become a slow survival strategy individual; individuals in a resourcepoor living environment will show a higher degree of psychological Insecurity, become an individual of fast survival strategy [37]. Individuals with fast survival strategies are generally more inclined to violate social norms, impulsivity and risk-taking [38]; individuals with slow survival strategies are generally more inclined to follow social norms, being cautious and conservative [39]. When faced with risky decision-making, individuals with fast survival strategies are relatively short-sighted and aggressive, while individuals with slow survival strategies are relatively long-term and cautious [39]. Risk Sensitivity Theory (RST) pointed out that when facing the gap between feeling reality and ideal in a scarce situation, in order to meet needs and goals, individuals will choose high-risk programs to reduce the gap [40]. For example, in the experimental gambling task, when the minimum requirement for rewards is increased, in order to achieve higher requirements, participants with scarcity perception will become more willing to make high-risk, high-reward choices [41]. Based on this, this study argues that migrant workers, as the social bottom group, tend to adopt fast survival strategies when they perceive the PSOS, and they are more willing to choose risk-taking tendency to change the status quo. Therefore, we assume that:

H1: The PSOS caused by COVID-19 will promote the risk-taking tendency of migrant workers.

\subsection{The mediating role of cognitive reflection}

The effectiveness of behavioral decision-making depends on the cognitive ability of decision-makers 
[42]. Executive control refers to the ability of individual to plan, focus, restrain behavior and control impulse [30], which exists in the cognitive ability process of individual management. Cognitive reflection is an important indicator of executive control [43]. It refers to the use of analytical thinking rather than intuitive thinking in judgment and risk decision-making [42]. It is a reflection of the individual's ability to suppress intuition. It has also been proved by a large number of studies that it has very good predictability for risk decision-making and risk-taking tendency [44].

The Scarcity Mindset Theory believes that the scarcity of resources causes individuals to have a scarce mentality. The scarce mentality causes the individual to have a "tunneling" phenomenon by affecting the allocation of individual attention resources [30]. Mani et al.'s research shows that problems related to scarcity consume individual mental resources, the mental resources that can be consumed by other problems are reduced, and the individual's cognitive ability will be significantly reduced. Mullainathan and Shafir proved through experimental research that scarce mentality will affect an individual's cognitive bandwidth, mainly including cognitive capacity and executive control [30]. Based on this, we believe that the migrant workers' PSOS caused by the pandemic will lead to the decline of their cognitive ability and weaken their ability to analyze, judge and logically reason; at the same time, the scarce mentality will lead to the decline of the migrant workers' cognitive reflection ability and weaken their restraining behavior and impulse to control ability, which in turn produces a higher risk-taking tendency. We propose the following hypothesis:

$\mathrm{H} 2$ : Cognitive reflection plays a mediating role in the impact of the PSOS on risk-taking tendency of migrant workers: the PSOS promotes migrant workers' risk-taking tendency by hindering cognitive reflection.

\subsection{The mediating role of sense of unfairness}

The sense of unfairness is the product of social comparison. The PSOS is often the relative individual feeling. Relativity comes from the comparison with the state of self or others, and is a process of social comparison [45]. Social Comparison Theory [46] believes that when there is no objective evaluation standard, individuals will determine their relative positions through comparison with others [46]; the directions of individual social comparison mainly include upward comparison, parallel comparison and downward comparison [36]. Previous studies believed that individuals first tended to upward social comparison, that means, compared with people with higher or better grades than their own: when the current status of the individual is consistent with the upward comparison goal, it will produce an assimilation effect, that means, the individual's self-worth will be improved; otherwise, it will produce a comparison effect, That is, individuals will produce negative self-evaluation [47]. In addition, the social comparison process involves whether the individual has the maximum benefit relative to others [47], therefore, the upward social comparison will affect the individual's sense of fairness and behavioral decision-making [48]. From the scarcity point of view, compared with higher class levels, migrant workers will have a higher PSOS, and the more they feel unfair. Although the mechanism of the causality between individual sense of fairness and risk-taking tendency is not clear, the promotion effect of sense of unfairness on risk-taking tendency has been verified [49]. There is a lot of evidence that unfairness can lead to risk-taking tendency by individuals [50], and violence and criminal behavior mostly occur when people desire to succeed [51]. In gambling games, the higher the degree of economic inequity, the more inclined participants are to take greater risks to obtain higher returns. This risk-taking tendency is driven by upward social comparison; countries or regions with higher levels of unfairness. The more residents tend to take risks, this risk-taking tendency is driven by "unfairness compared with higher income classes" [51, 52], and migrant workers are at the bottom of society in terms of economy, status, and access to public resources. This kind of upward comparison can stimulate its unfairness more. To sum up, it can be deduced from the existing research results that migrant workers' PSOS will trigger their sense of unfairness, and then promote their risk-taking tendency. Based on this, we propose the following hypothesis:

H3: Sense of unfairness plays a mediating role in the impact of the PSOS on the risk-taking tendency of migrant workers: the PSOS promotes migrant workers' risk-taking tendency by trigger their unfairness.

\subsection{The mediating role of expected benefits}

Under the risk-return framework of psychology, the individual's judgment on the expected benefits of a certain risk-taking tendency is an important 
indicator for predicting that the individual may participate in a certain risk-taking tendency in the future [53-55]. Therefore, under the risk-benefit framework, whether or not to take risks often depends on people's assessment of the expected benefits and the size of risks, that means, risk-taking tendency is a function of expected benefits: The greater the expected benefits, the greater the propensity to take risks, the smaller the expected benefits, the smaller the propensity to take risks.

The Scarcity Mentality Theory believes that the scarcity of different resources will trigger risk-taking tendency, and the impact of resource scarcity on individual risk-taking tendency mainly comes from the impact of resource scarcity on the risk or profit and loss judgment process. People usually rely on heuristics and experience to solve risk decisionmaking problems [56]. At the level of the nervous system, the risk-taking decision-making process relies on the learning system of the brain's nerves to make value judgments and optimal choices [57]. Williams et al. recorded the activity of the medial frontal cortex of 17 adults. The experimental results showed that the P300 amplitude of the participants in the scarce group showed significant differences in the process of estimating gains and losses. The scarcity perception enhanced the participants' perception of the value of profit and loss [58]. Therefore, this study believes that the judgment of the expected benefits of risk-taking tendency will be affected by scarcity perception. During the COVID-19 pandemic, changes in the society and living environment will make migrant workers in a state of the PSOS, which in turn affects their cognitive ability and complete and rational judgment of external information, thereby amplifying the judgment of the expected benefits of risk-taking tendency, and ultimately promoting their risk-taking tendency. Based on this, we propose the following hypothesis:

$\mathrm{H} 3$ : Expected benefits plays a mediating role in the impact of the PSOS on the risk-taking tendency of

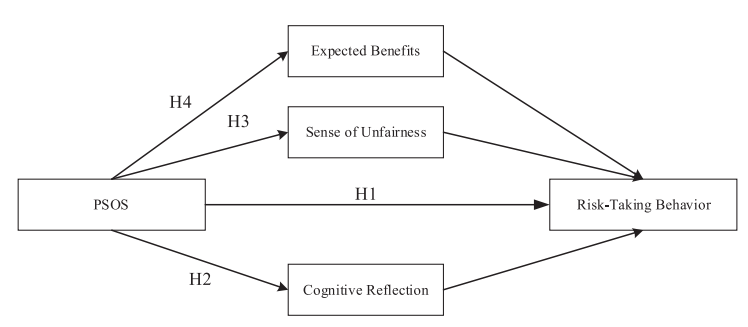

Fig. 1. Conceptual model diagram of this research. migrant workers: the PSOS promotes migrant workers' risk-taking tendency by amplifying the judgment of the expected benefits of risk-taking tendency.

According to the above hypothesis deduction, a comprehensive conceptual model of this study is proposed, as shown in Fig. 1.

\section{Research methods and results}

\subsection{Study 1}

\subsubsection{Participants}

In Study 1, 514 migrant workers were recruited in Dalian, China. Dalian is an important port city in China, with a GDP of 700.170 billion RMB in 2019. It has developed industry and attracts a large number of migrant workers to work here. On July 22, another local confirmed case occurred 111 days later in Dalian. Although the local government quickly closed schools, subways, entertainment venues, and appealed to residents not to leave Dalian, 87 confirmed cases were still added in just 10 days. On July 23 , the government announced that the city was in a state of war, which also released the signal of the recurrence of the pandemic in Dalian, causing a certain degree of panic among citizens and worries of other provinces and cities. All regions in China have listed Dalian as a high-risk area and implemented a 14 days isolation system for its visitors. In this context, we conducted a survey on 2103 migrant workers in Dalian from July 29 to August 4 on their sense of ontological security and risk-taking tendency. The sample information is shown in Table 2.

\subsubsection{Experimental design}

First, the researchers explained the concept of ontological security to the participants to ensure that the participants fully understood the concept, and then randomly assigned the participants to the scarcity group that initiated the PSOS and the control group that did not activate the PSOS. Then, we record the basic information of the participants (gender, age, job, income, and education).

Secondly, Study 1 uses stimulating materials to stimulate the subject's PSOS. Participants in the scarcity group were asked to read a piece of written material about the negative impact of the pandemic on the economy, life and safety of migrant workers to trigger their PSOS. Participants in the control group read a piece of written material on China's achievements in the fight against the pandemic and migrant 
Table 2

Descriptive statistics of samples, Study $1(\mathrm{~N}=514)$

\begin{tabular}{lccccccc}
\hline Characteristics & Classification & \multicolumn{2}{c}{ Sample } & Characteristics & Classification & Sample \\
\cline { 3 - 4 } & & Number & $\begin{array}{c}\text { Percentage } \\
\%\end{array}$ & & & $\begin{array}{c}\text { Number } \\
\text { Percentage } \\
\%\end{array}$ \\
\hline Gender & Male & 328 & $63.81 \%$ & Job & Manufacturing & 256 & $49.81 \%$ \\
& Female & 186 & $36.19 \%$ & & Service industry & 138 & $26.85 \%$ \\
Age & 25 years and under & 64 & $12.45 \%$ & & Freelance & 74 & $14.40 \%$ \\
& 26-30 years old & 172 & $33.46 \%$ & & Other & 46 & $8.94 \%$ \\
& 31-35 years old & 160 & $31.23 \%$ & Monthly & 3000 RMB and below & 38 & $7.39 \%$ \\
& 26-40 years old & 74 & $14.40 \%$ & income & 3000-4500 RMB & 150 & $29.19 \%$ \\
\multirow{4}{*}{ Education } & Over 40 years old & 44 & $8.56 \%$ & level & 4500-6000 RMB & 210 & $40.85 \%$ \\
& High school and below & 306 & $59.53 \%$ & & 6000-8500 RMB & 68 & $13.23 \%$ \\
& Junior college & 208 & $40.47 \%$ & & Over 8500 RMB & 48 & $9.34 \%$ \\
\hline
\end{tabular}

workers are returning to normal life in an orderly manner. Both groups of participants were asked to repeat the content after reading the material and talk about their feelings.

Finally, the participants in the scarcity group and the control group were measured for the Overall Risktaking Tendency, Cognitive Reflection and Sense of Unfairness. Table 3 contains an overview of all scale items and their psychometric measures. In Study 1, we used the Cognitive Refection Test revised by Frederick (2005) to measure the cognitive reflection of migrant workers [59]. The CRT scale is a measurement tool that has been proven by a large number of studies to effectively measure individual intuition suppression and cognitive reflection, and includes 3 test questions. The respondent was asked to choose the correct answer for the 6 calculation questions (for example, If it takes 5 machines 5 minutes to make 5 widgets, how long would it take 100 machines to make 100 widgets?), each test will provide two for the respondent Options (for example, $100 \mathrm{~min}$ utes or 5 minutes), where the correct option reflects prudent thinking (for example, 5 minutes), and the incorrect option reflects intuition (for example, 100 minutes). The respondent scores 1 point for each correct answer, and the final score is the CRT score (0-3 points).

\subsubsection{Result}

\section{(1) Manipulation Test}

For the analyses, we conducted $t$-test to compared the scores of the PSOS of 514 migrant workers. The results show that there is a significant difference in the PSOS between the scarcity group and

Table 3

Scale items and psychometric measures, Study 1

\begin{tabular}{|c|c|c|c|}
\hline Construct & Operationalization & Adopted from & Validity \\
\hline $\begin{array}{l}\text { Risk-taking } \\
\text { tendency }\end{array}$ & $\begin{array}{l}\text { 1. Taking risks makes life more fun. } \\
\text { 2. My friends would say that I'm a risk taker. } \\
\text { 3. I enjoy taking risks in most aspects of my life. } \\
\text { 4. I commonly make risky decisions. } \\
\text { 5. I am a believer of taking chances. }\end{array}$ & {$[60]$} & $\begin{array}{r}\mathrm{CA}=0.852 \\
\mathrm{CR}=0.947 \\
\mathrm{AVE}=0.751\end{array}$ \\
\hline PSOS & $\begin{array}{l}\text { 1. My ontological security is scarce. } \\
\text { 2. I don't have enough ontological security. } \\
\text { 3. I need to acquire ontological security. }\end{array}$ & {$[61]$} & $\begin{array}{r}\mathrm{CA}=0.874 \\
\mathrm{CR}=0.842 \\
\mathrm{AVE}=0.722\end{array}$ \\
\hline $\begin{array}{l}\text { Sense of } \\
\text { unfairness }\end{array}$ & $\begin{array}{l}\text { 1. The society was fair to me. } \\
\text { 2. I feel like living in an atmosphere of fairness. }\end{array}$ & {$[62]$} & $\begin{array}{r}\mathrm{CA}=0.867 \\
\mathrm{CR}=0.828 \\
\mathrm{AVE}=0.701\end{array}$ \\
\hline Cognitive reflection & $\begin{array}{l}\text { 1. A bat and a ball cost } \$ 1.10 \text { in total. The bat costs } \$ 1.00 \\
\text { more than the ball. How much does the ball cost? ( } \$ 1.05 \text { or } \$ 0.05) \\
\text { 2. If it takes } 5 \text { machines } 5 \text { minutes to make } 5 \text { widgets, how long would } \\
\text { it take } 100 \text { machines to make } 100 \text { widgets? ( } 100 \text { minutes or } 5 \text { minutes) } \\
\text { 3. In a lake, there is a patch of lily pads. Every day, the patch doubles in size. } \\
\text { If it takes } 48 \text { days for the patch to cover the entire lake, how long would } \\
\text { it ake for the patch to cover half of the lake? ( } 47 \text { days or } 24 \text { days) }\end{array}$ & [59] & $\begin{array}{l}\mathrm{CA}=0.857 \\
\mathrm{CR}=0.820 \\
\mathrm{AVE}=0.675\end{array}$ \\
\hline
\end{tabular}

Note: All items were measured with 7-point Likert scales (1="strongly disagree" to $7=$ "strongly agree"). CA=Cronbach's alpha, $\mathrm{CR}=$ congeneric reliability, $\mathrm{AVE}=$ average variance extracted. 
the control group in Study 2. $\mathrm{M}_{\text {scarcitygroup }}=4.56$, $\mathrm{M}_{\text {controlgroup }}=2.53, \mathrm{t}(512)=18.54, p<0.001$. It shows that Study 2 successfully manipulated the PSOS. A confirmatory factor analysis (CFA) indicates adequate model fit (root mean square error of approximation [RMSEA] $=0.048$, confirmatory fit index $[\mathrm{CFI}]=0.965$, standardized root mean residual $[\mathrm{SRMR}]=0.048)$. In addition, the multi-item measures all achieved a high level of convergent validity, with average variance extracted (AVE) values greater than 0.6 and congeneric reliability (CR) values greater than 0.8 (see Table 3 ). To establish discriminant validity, we confirmed that each construct's AVE was greater than its squared latent variable correlations with any other construct.

(2) Hypothesis Test

First of all, we conducted an independent sample $t$ test on the risk-taking tendency of the scarcity group and the control group. The results showed that in the overall risk-taking tendency, the scores of the scarcity group and the control group were significantly different, $\mathrm{M}_{\text {scarcitygroup }}=4.08, \mathrm{M}_{\text {controlgroup }}=2.34, \mathrm{t}(512)$ $=18.265, p<0.001$. Therefore, we perceived the PS OS can significantly promote the risk-taking tendency of migrant workers, and $\mathrm{H} 1$ has been verified. Then, we compared the scores of cognitive reflection and sense of unfairness between the two groups in Study 1 . The results showed that the average score of cognitive reflection in the scarcity group is 1.68 , while that in the control group is $3.77, \mathrm{t}(512)=12.538$, $P<0.001$, indicating that PSOS would reduce the ability of cognitive reflection. In terms of sense of unfairness, $\mathrm{M}_{\text {scarcitygroup }}=3.09, \mathrm{M}_{\text {controlgroup }}=2.10$, $\mathrm{t}(512)=8.254, P<0.001$, indicating that PSOS will promote individuals to have more sense of unfairness. The statistical data are shown in Fig. 2.

In order to test the mediating role of cognitive reflection and sense of unfairness, Study 1 normalized all variables and followed the mediating analysis

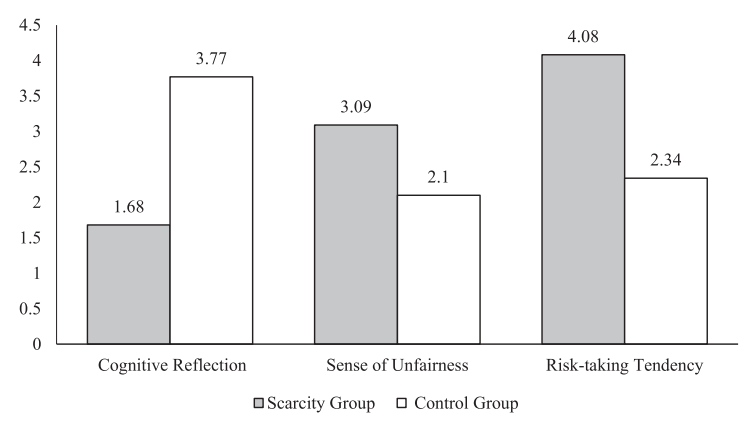

Fig. 2. Comparison of two groups of data in Study 1. procedure [63] proposed by Zhao et al., using Bootstrap method to test the mediating effect. The results show that the mediating effect of cognitive reflection is established, the indirect effect is $0.158,95 \%$ BootCI $(\mathrm{LLCI}=0.077, \mathrm{ULCI}=0.384$, excluding 0$)$; the mediating effect of sense of unfairness is also established, the indirect effect is $0.182,95 \%$ BootCI $(\mathrm{LLCI}=0.064, \mathrm{ULCI}=0.325$, excluding 0 ). After controlling the mediators, the direct influence of the independent variables on the risk-taking tendency of migrant workers is still established, the indirect effect is $0.278,95 \%$ BootCI ( $\mathrm{LLCI}=0.194$, ULCI $=0.528$, excluding 0 ), This shows that cognitive reflection and sense of unfairness play a partial mediating role in the impact of the PSOS on migrant workers' risk-taking tendency. Therefore, $\mathrm{H} 2, \mathrm{H} 3$ is supported, and the specific regression coefficients are shown in Table 4.

\subsection{Study 2}

In order to further verify the influence mechanism of PSOS on migrant workers' risk-taking tendency, Study 2 uses the Domain-Specific Risk Taking Scale to measure the effect of PSOS on risk-taking tendency of migrant workers in five specific risk-taking areas, and verified $\mathrm{H} 4$.

\subsubsection{Participants}

In Study 2, 375 migrant workers were recruited in Chengdu, China. Chengdu is one of the central cities in Southwestern China, where attracts many migrant workers every year. After the first wave of pandemic in China from January to March, there are no more local infected case. 358 effective participants were obtained after screening the completion rate of tasks, the sample information is shown in Table 5.

\subsubsection{Experimental design}

Study 2 consists of 3 experimental steps. First, randomly assign participants to the scarcity group and the control group, then record the participant's basic information (emotional state, gender, age, and income). Secondly, in order to prevent the participants from having different perceptions of the stimulating materials (used in Study 1) for the PSOS, Study 2 uses the episodic recall task to trigger the participants' PSOS. Participants in the scarcity group were asked to think and answer a series of questions to elicit scarcity perceptions. Participants in the control group were asked to think and answer non-scarcity manipulations that were not related to resource scarcity. Finally, the participants in the scarcity group and 
Table 4

Model test of mediating effect of cognitive reflection and sense of unfairness $(\mathrm{N}=514)$

\begin{tabular}{|c|c|c|c|c|c|c|c|c|}
\hline \multirow[t]{2}{*}{ Variable } & \multicolumn{2}{|c|}{ Total effect } & \multicolumn{2}{|c|}{$\begin{array}{l}\text { The mediating } \\
\text { role of cognitive } \\
\text { reflection }\end{array}$} & \multicolumn{2}{|c|}{$\begin{array}{c}\text { The mediating } \\
\text { role of sense } \\
\text { of unfairness }\end{array}$} & \multicolumn{2}{|c|}{ Direct effect } \\
\hline & $B$ & $S E$ & $B$ & $S E$ & $B$ & $S E$ & $B$ & $S E$ \\
\hline \multicolumn{9}{|l|}{ Controlled variable } \\
\hline Gender & -0.018 & 0.021 & -0.021 & 0.025 & $0.118^{*}$ & 0.058 & -0.056 & 0.041 \\
\hline Age & -0.042 & 0.015 & 0.042 & 0.044 & 0.032 & 0.016 & -0.021 & 0.032 \\
\hline Emotional & -0.052 & 0.044 & 0.073 & 0.036 & -0.025 & 0.013 & 0.042 & 0.028 \\
\hline Income & -0.036 & 0.020 & 0.052 & 0.025 & -0.058 & 0.027 & -0.035 & 0.015 \\
\hline \multicolumn{9}{|l|}{ Independent variable } \\
\hline PSOS & $0.538^{* * *}$ & 0.242 & $-0.332 * * *$ & 0.232 & $0.342^{* * *}$ & 0.152 & $0.278^{* * *}$ & 0.153 \\
\hline \multicolumn{9}{|l|}{ Mediator } \\
\hline Cognitive reflection & & & & & & & $-0.210^{* *}$ & 0.135 \\
\hline Sense of unfairness & & & & & & & $0.323^{* * *}$ & 0.160 \\
\hline Adjusted $R^{2}$ & \multicolumn{2}{|c|}{0.328} & \multicolumn{2}{|c|}{0.315} & \multicolumn{2}{|c|}{0.366} & \multicolumn{2}{|c|}{0.482} \\
\hline $\mathrm{F}$ & \multicolumn{2}{|c|}{$135.28^{* * *}$} & \multicolumn{2}{|c|}{$121.32^{* * *}$} & \multicolumn{2}{|c|}{$154.27^{* * *}$} & \multicolumn{2}{|c|}{$168.37^{* * *}$} \\
\hline
\end{tabular}

Table 5

Descriptive statistics of samples, Study $2(\mathrm{~N}=358)$

\begin{tabular}{lccc}
\hline Characteristics & & \multicolumn{2}{c}{ Sample } \\
\cline { 3 - 4 } & & Number & $\begin{array}{c}\text { Percentage } \\
\%\end{array}$ \\
\hline Gender & Male & 197 & $55.03 \%$ \\
Age & Female & 161 & $44.97 \%$ \\
& 25 years and under & 57 & $15.92 \%$ \\
& 26-30 years old & 104 & $29.05 \%$ \\
& 31-35 years old & 122 & $34.08 \%$ \\
Education & 36-40 years old & 40 & $11.17 \%$ \\
& Over 40 years old & 35 & $9.78 \%$ \\
Employment & High school and below & 172 & $48.04 \%$ \\
& Junior college & 186 & $51.96 \%$ \\
& Manufacturing & 128 & $35.75 \%$ \\
Monthly & Service industry & 103 & $28.77 \%$ \\
income level & Freelance & 48 & $13.41 \%$ \\
& Other & 79 & $22.07 \%$ \\
& 3000 RMB and below & 48 & $13.40 \%$ \\
& 3000-4500 RMB & 95 & $26.54 \%$ \\
& 4500-6000 RMB & 135 & $37.71 \%$ \\
& 6000-8500 RMB & 65 & $18.16 \%$ \\
& Over 8500 RMB & 15 & $4.19 \%$ \\
\hline
\end{tabular}

the control group were individually measured for risk-taking tendency, cognitive reflection, expected benefits, and sense of unfairness.

\subsubsection{Variable measurement}

In Study 2, the measurement scales of cognitive reflection, sense of unfairness, emotional state, and social norm recognition of the subjects are the same as in Study 1, and not be introduced here. This section only describes the manipulation methods of PSOS, the measurement methods of expected benefits and the risk-taking tendency in domain-specific fields.

(1) Manipulation of PSOS

We explain the concept of ontological security to the participants. After ensuring that the participants fully understand the concept, the Study 2 uses the Episodic recall task to stimulate participants' PSOS [61, 64]. In the recall task, the participants in the scarcity group were asked to recall three-four episodes during the pandemic when the ontological

Table 6

Test on the mechanism of PSOS on risk-taking tendency in specific domains $(\mathrm{N}=358)$

\begin{tabular}{|c|c|c|c|c|c|c|c|}
\hline \multirow[t]{2}{*}{ Domain-specific } & \multirow[t]{2}{*}{ Category } & \multirow[t]{2}{*}{ Effect } & \multirow[t]{2}{*}{ SE } & \multirow[t]{2}{*}{$\mathrm{t}$} & \multirow[t]{2}{*}{$p$} & \multicolumn{2}{|c|}{$95 \% \mathrm{CI}$} \\
\hline & & & & & & LLCI & ULCI \\
\hline \multirow[t]{4}{*}{ Recreational } & Direct effect & 0.260 & 0.070 & 3.709 & 0.000 & 0.119 & 0.401 \\
\hline & Mediating effect of cognitive reflection & 0.264 & 0.115 & - & Excluding 0 & 0.008 & 0.262 \\
\hline & Mediating effect of expected benefits & 0.183 & 0.256 & - & Excluding 0 & 0.107 & 0.576 \\
\hline & Mediating effect of sense of unfairness & 0.105 & 0.042 & - & Excluding 0 & 0.033 & 0.199 \\
\hline \multirow[t]{4}{*}{ Financial } & Direct effect & 0.219 & 0.055 & 4.015 & 0.000 & 0.110 & 0.329 \\
\hline & Mediating effect of cognitive reflection & 0.215 & 0.061 & - & Excluding 0 & 0.111 & 0.350 \\
\hline & Mediating effect of expected benefits & 0.317 & 0.076 & - & Excluding 0 & 0.171 & 0.449 \\
\hline & Mediating effect of sense of unfairness & 0.033 & 0.021 & - & Excluding 0 & 0.003 & 0.082 \\
\hline \multirow[t]{4}{*}{ Ethical } & Direct effect & 0.314 & 0.066 & 4.728 & 0.000 & 0.181 & 0.447 \\
\hline & Mediating effect of cognitive reflection & 0.120 & 0.058 & - & Excluding 0 & 0.014 & 0.239 \\
\hline & Mediating effect of expected benefits & 0.241 & 0.100 & - & Excluding 0 & 0.096 & 0.497 \\
\hline & Mediating effect of sense of unfairness & 0.099 & 0.042 & - & Excluding 0 & 0.026 & 0.189 \\
\hline
\end{tabular}


security was scarce, and then the participants needed to write down the details of 2 of the episodes, including feelings, influences and experiences at the time. Participants in the control group were asked to recall three-four events that occurred in the past week and choose two to write down the details separately.

(2) Measurement of individual's risk-taking tendency

Study 2 uses the Domain-Specific Risk-Taking Scale to measure individual risk-taking tendency propensity [54]. The Domain-Specific Risk-Taking Scale includes risk-taking tendency scale and expected benefits scale. Each scale contains 6 daily behaviors from 5 fields of Social, Recreational, Financial, Health/Safety and Ethical, with a total of 30 behavior descriptions. The risk-taking tendency scale uses "1 (impossible) to 7 (very possible)" to measure the possibility of producing a specific behavior; the expected return scale uses " 1 (almost no benefit) to 7 (benefit is very large)" to assess the expected benefit level of a particular behavior.

\subsubsection{Result}

\section{(1) Manipulation Test}

For the analyses, we conducted $t$-test to compared the scores of the PSOS of 358 migrant workers. The results show that there is a significant difference in the PSOS between the scarcity group and the control group in Study 2. $\mathrm{M}_{\text {scarcitygroup }}=4.36, \mathrm{M}_{\text {controlgroup }}$ $=2.11, \mathrm{t}(356)=22.446, p<0.001$. It shows that Study 2 successfully manipulated the PSOS. Cohen's $d=0.707$, power $=0.996$, indicating that the sample size of Study 2 meets the requirements of the test. The reliability analysis of the risk-taking tendency scale in domain-specific fields shows that the internal consistency coefficient is acceptable in five fields: Cronbach's $a=0.887$ in social field; Cronbach's $a=0.934$ in recreational field; Cronbach's $a=0.946$ in financial field; Cronbach's $a=0.849$ in health/ safety field; Cronbach's $a=0.931$ in ethical field. We used $t$-test to compare the emotional states and recognize social norms of the two groups, the results showed that the emotional states of participants in different groups were not significantly different, $\mathrm{M}_{\text {scarcitygroup }}=0.34, \mathrm{M}_{\text {controlgroup }}=0.61, \mathrm{t} \quad(356)=$ $1.416, P>0.05$. It is proved that the participants' emotional states do not affect the results of Study 2.

(2) Hypothesis Test

First, an independent sample $t$-test was performed on the risk behavior of the scarcity group and the control group. The results showed that the scores of risk-taking tendency of the scarce group and the control group were significantly different in the fields of recreational, financial and ethical. In the field of recreational, $\mathrm{M}_{\text {scarcitygroup }}=3.94, \mathrm{M}_{\text {controlgroup }}=$ $2.40, \mathrm{t}(356)=9.531, \quad p<0.05 ; \quad$ in the field of financial, $\mathrm{M}_{\text {scarcitygroup }}=4.25, \mathrm{M}_{\text {controlgroup }}=2.38$, $\mathrm{t}(356)=10.572, p<0.05$; in the field of ethical, $\mathrm{M}_{\text {scarcitygroup }}=2.933, \mathrm{M}_{\text {controlgroup }}=1.511, \mathrm{t}(356)=$ $9.989, p<0.05$. However, in the social field and the health/safety field, the scores of risk-taking tendency of the two groups were not significantly different. In the field of social, $\mathrm{M}_{\text {scarcitygroup }}=3.220$, $\mathrm{M}_{\text {controlgroup }}=3.538, \mathrm{t}(356)=1.465, p>0.05$, homogeneity of variance; in the field of health/safety, $\mathrm{M}_{\text {scarcitygroup }}=2.176, \mathrm{M}_{\text {controlgroup }}=2.204, \mathrm{t}(356)=$ $0.161, P>0.05$. Therefore, the PSOS can significantly promote the risk-taking tendency of migrant workers in the fields of recreational, financial and ethical, $\mathrm{H} 1$ is verified.

In order to test the mediating role of cognitive reflection, sense of unfairness and expected benefits, Study 2 normalized all variables and followed the mediating analysis procedure [63] proposed by Zhao et al., using Bootstrap method to test the mediating effect. The results show that the mediating effect of cognitive reflection, sense of unfairness and expected benefits is established in the fields of recreational, financial and ethical. In the field of recreational, the indirect effect of cognitive reflection is $0.264,95 \%$ BootCI $(\mathrm{LLCI}=0.008, \mathrm{ULCI}=0.262$, excluding 0$)$; the indirect effect of sense of unfairness is 0.105 , $95 \%$ BootCI $(\mathrm{LLCI}=0.033$, ULCI $=0.199$, excluding 0 ); the indirect effect of expected benefits is 0.183 , $95 \%$ BootCI $(\mathrm{LLCI}=0.107, \mathrm{ULCI}=0.576$, excluding 0) After controlling the mediators, the direct effect of the independent variable on the dependent variable is still established, the direct effect is 0.260 , $t=3.709, p<0.001$, that means, cognitive reflection, sense of unfairness and expected benefits play a part of the mediating effect in the impact of the PSOS on migrant workers' risk-taking tendency in the field of recreational. In the field of financial, the indirect effect of cognitive reflection is $0.215,95 \%$ BootCI $(\mathrm{LLCI}=0.111$, ULCI $=0.350$, excluding 0$)$; the indirect effect of sense of unfairness is $0.033,95 \%$ BootCI $(\mathrm{LLCI}=0.003, \mathrm{ULCI}=0.082$, excluding 0$)$; the indirect effect of expected benefits is $0.317,95 \%$ BootCI $(\mathrm{LLCI}=0.171, \mathrm{ULCI}=0.449$, excluding 0 ) After controlling the mediators, the direct effect of the independent variable on the dependent variable is $0.219, t=4.015, p<0.001$, that means, cognitive reflection, sense of unfairness and expected benefits 
play a part of the mediating effect in the impact of the PSOS on migrant workers' risk-taking tendency in the field of financial. In the field of ethical, the indirect effect of cognitive reflection is $0.120,95 \%$ BootCI $(\mathrm{LLCI}=0.014$, ULCI $=0.239$, excluding 0$)$; the indirect effect of sense of unfairness is $0.099,95 \%$ BootCI (LLCI $=0.026$, ULCI $=0.189$, excluding 0); the indirect effect of expected benefits is $0.241,95 \%$ BootCI (LLCI $=0.096$, ULCI $=0.497$, excluding 0) After controlling the mediators, the direct effect of the independent variable on the dependent variable is $0.314, t=4.728, p<0.001$, that means, cognitive reflection, sense of unfairness and expected benefits play a part of the mediating effect in the impact of the PSOS on migrant workers' risk-taking tendency in the field of ethical. Therefore, H2-H4 are supported.

\section{Discussion}

The purpose of this study is to investigate the impact of disaster-induced scarcity perception on the bottom workers' risk-taking tendency and its mechanism. Combining with the background of the COVID-19 pneumonia pandemic, this study focuses on the Chinese migrant workers who are most affected by the pandemic. Most of these laborers leave their hometowns to seek employment in the city, and they are usually manual workers with low wages. It is highly mobile and lacks basic vocational skills $[12,14]$. During the pandemic, not only did income worsen, but it was also more susceptible to discrimination. Therefore, they are more prone to the state of PSOS in crises, and whether and how this scarce state changes their risk-taking tendency may affect the stability of society and enterprises, which is also a key issue that governments and enterprises want to pay attention to. To our knowledge, this article is one of the few studies on the impact of the COVID-19 pandemic on the behavior of the migrant workers.

In this research, through two studies, it was verified that the PSOS has a significant role in promoting the risk-taking tendency of migrant workers. Different from previous studies, this research explores the impact of ontological security on individual behavior during pandemic situations from the Scarcity Mindset Theory. Life History Theory believes that individuals in resource-scarce environments will show a higher degree of psychological insecurity and choose a fast survival strategy [37]. Individuals with fast survival strategies are generally more inclined to violate social norms, impulsivity and risk-taking [38]. Risk
Sensitivity Theory points out that when facing the gap between reality and ideal in a scarce situation, in order to meet the needs and goals, individuals will choose high-risk programs to reduce the gap [40]. The research results of this research also support these two theories, that during the pandemic, the PSOS is the same as the scarcity of other resources, such as the scarcity perception of money [41], which will lead individuals to choose more risk-taking tendency.

Further, this research explains the mechanism of the impact of the PSOS on the risk-taking tendency of migrant workers from the perspective of cognitive reflection, sense of unfairness and expected benefits. Decision-makers' cognitive reflection is the reflection of an individual's ability to suppress intuition [44], which determines the individual's ability to control impulse [30], The Scarcity Mindset Theory believes that the scarcity mindset will affect the individual's cognitive bandwidth, and the individual's cognitive ability will be significantly reduced, causing the individual to have a "tunneling" phenomenon and lead to bad behavior [30]. The scarcity perception of migrant workers' ontological security caused by the pandemic will lead to the decline of migrant workers' cognitive reflection ability, weaken their ability of restraining behavior and controlling impulse, and then produce higher risk-taking tendency. Secondly, during the pandemic period, the migrant workers at the bottom of the society are more likely to feel unfair through upward comparison. From the perspective of perceived scarcity, this sense of unfairness will aggravate the perception of resource scarcity and then lead to higher risk-taking tendency [49]. On the other hand, migrant workers' PSOS magnifies their judgment of expected benefits on risk-taking tendency, thus promoting their risk-taking tendency.

Finally, this research also explores the mechanism of the impact of the PSOS on migrant workers' risk-taking tendency in five special fields: Social, Recreational, Financial, Health/Safety and Ethical. The research results show that this promotion mechanism is established in the three risk-taking fields of Recreational, Financial and Ethical, which to a certain extent reflects the migrant workers during the pandemic period: Migrant workers hope to get rid of this ontological insecurity as soon as possible through income recovery. Therefore, it will induce them to take more risks in this field, for example, prefer to choose higher risk fund stocks and more willing to participate in gambling. In order to alleviate this insecurity and economic pressure, migrant workers' acceptance of stimulating entertainment 
will increase; while in the field of morals, changes in the rhythm of life and the environment caused by the pandemic have increased people's tolerance for unethical behavior, and discrimination from others may also lead to their revenge mentality in the moral field. And this process is caused by the decline of cognitive reflection, the increase of unfairness, and the amplification of expected benefits. However, this mechanism does not seem to be established in the fields of Social and Health/Safety. This research believes that this may be affected by traditional Chinese culture. Confucian culture guides the Chinese to pay more attention to group self rather than independent self. People generally care more about others' evaluation of themselves. Therefore, they usually show humility and kindness in communication rather than taking risky ways [65]. At the same time, the COVID-19 pandemic threatens the health of individuals and makes individuals pay special attention to health issues. In Chinese values, ensuring life safety is a responsibility and filial piety [66], so migrant workers who run for their families will not take risky behaviors in the health/safety field during the pandemic.

\subsection{Theoretical contribution}

The theoretical value and innovation of this research are mainly reflected in two aspects. On the one hand, we demonstrate the promotion effect of the PSOS on adventure behavior. In previous studies on ontological security, the main focus was on the direct impact of natural disasters on people's psychology. For example, to explore the environmental change factors that affect the ontological security, and the psychological stress after the ontological security feels threatened [21, 22]. Few studies have investigated the impact of the ontological sense of scarcity on individual behavior from the perspective of scarce mentality. In this study, ontology security is regarded as a resource. Based on the theory of resource scarcity, the relationship between the PSOS and risk-taking tendency is derived, which complements the research in related fields and enriches the theory of ontological security. On the other hand, this study explains the internal mechanism of the impact of the PSOS on migrant workers' risk-taking tendency, confirms the mediating role of cognitive reflection, sense of unfairness and expected benefits. At present, there are not many literatures about the impact of COVID-19 on the psychology and behavior of the bottom workers. The conclusion of this study not only fills the influence mechanism of cognitive reflection, sense of unfairness and expected benefits in the relationship between the PSOS and the risk-taking tendency of migrant workers, but also provides a new research idea for the study of resource scarcity and poor people's behavior.

\subsection{Management implications}

(1) The implications to the individual. The conclusions of this study can help migrant workers avoid individual negative risk-taking tendency during the pandemic period, and improve their life wellbeing and job performance. In this study, the PSOS is defined as a subjective feeling that "ownership" is less than "need", which may happen to anyone. The PSOS induces the sense of unfairness, enlarges the expected benefit of risk-taking and reduces the cognitive reflective ability of individuals, which will promote the risk-taking tendency of migrant workers in their daily life and workplace. Therefore, after clarifying the psychological mechanism of perceived risk-taking tendency effect of PSOS, individuals can guide their own behavior, alleviate the sensitivity of PSOS, and avoid negative risk-taking tendency.

(2) The implications to enterprises or organizations. The conclusions of this study can help organizations to improve management ability and prevent potential workplace and social bad behaviors. In this study, the scarcity perception of migrant workers' ontological security caused by COVID19 pandemic will reduce the individual's cognitive ability and amplify the expected risk benefits. It is not conducive to the improvement of organizational performance by inducing unfairness and promoting individual risk-taking tendency. After clarifying the negative emotions and pressure caused by the scarcity perception of migrant workers' ontological security on their positive work behaviors, enterprises should formulate appropriate strategies to alleviate migrant workers' ontological insecurity during the pandemic period and avoid the bad risk-taking tendency in the workplace by guiding the migrant workers to correctly treat the PSOS. The conclusion of this study also provides a new reference for policy-making departments to formulate livelihood policies and health work and life guidelines for residents during the pandemic period. This study reminds the pandemic prevention agencies in various countries that, in the case of a possible resurgence of 
the pandemic situation, the management departments should be alert to the risk-taking tendency of the underlying workers, which may be a secondary disaster caused by the pandemic.

\subsection{Limitations and future research directions}

Although this study has certain theoretical significance and practical value, but limited to time and resource factors, there are still some limitations. First of all, this study only focused on migrant workers, but the relationship between the PSOS and risk-taking tendency caused by the pandemic may also be applicable to other groups living at the bottom of society. In future research, other groups (such as the unemployed, the homeless) to investigate to further explore the mechanism of the PSOS on risk-taking tendency. Secondly, due to the pandemic, the amount of experimental samples in this study is not large, and the research design is slightly hasty. It does not take into account the impact of factors such as individual cognitive ability, cognitive attitude to the pandemic, and family burden of migrant workers. These elements can be further explored.

\section{Conclusion}

In this study, we found that the perceived scarcity of ontological security caused by the COVID-19 pneumonia will positively affect the risk-taking tendency of migrant workers. Cognitive reflection ability, sense of unfairness and expected benefits appeared to significantly mediating role in this process.

\section{Acknowledgments}

The authors are grateful to the editor and anonymous referees for insightful comments that significantly improved the paper. This work is supported by the China Scholarship Council (No.202007000062).

\section{Conflict of interest}

None to report.

\section{References}

[1] Prideaux B, Thompson M, Pabel A. Lessons from COVID-19 can prepare global tourism for the economic transformation needed to combat climate change. Tourism Geographies. 2020;22(3):667-78.

[2] Qiang Y, Jiale H, Jiang L, Yushi J. Research on the influence of the COVID-19 epidemic on work stress of returning workers in china: a study based on empirical analyses of industrial enterprises. Work. 2020; Pre-press: 1-13.

[3] Shariat A, Ghannadi S, Anastasio A, Rostad M, Cleland JA. Novel stretching and strength-building exercise recommendations for computer-based workers during the COVID-19 quarantine. Work. 2020; Pre-press:1-11.

[4] Omidi L, Moradi G, Mostofi Sarkari N. Risk of COVID19 infection in workplace settings and the use of personal protective equipment. Work. 2020;66(2):377-8.

[5] Abel T, McQueen D. The COVID-19 pandemic calls for spatial distancing and social closeness: not for social distancing. International Journal of Public Health. 2020;65(3):231.

[6] He J, He L, Zhou W, Nie X, He M. Discrimination and Social Exclusion in the Outbreak of COVID-19. International Journal of Environmental Research and Public Health. 2020;17(8):2933.

[7] Jahangiri M, Cousins R, Gharibi V. Let's get back to work: Preventive biological cycle management of the coronavirus in the workplace. Work. 2020; Pre-press:1-4.

[8] Kantamneni N. The impact of the COVID-19 pandemic on marginalized populations in the United States: A research agenda. Journal of Vocational Behavior. 2020;119:103439.

[9] Report on monitoring and investigation of migrant workers in China in 2018. Rural work communication. 2019;(11):403.

[10] Chan SH, Qiu HH. Loneliness, job satisfaction, and organizational commitment of migrant workers: empirical evidence from China. International Journal of Human Resource Management. 2011;22(5):1109-27.

[11] Ngok K. Serving Migrant Workers: A Challenging Public Service Issue in China1. Australian Journal of Public Administration. 2012;71(2):178.

[12] Li J, Rose N. Urban social exclusion and mental health of China's rural-urban migrants - A review and call for research. Health and Place. 2017;48:20-30.

[13] An F, Broadbent K, Yuan F. Employment inequality among women migrant workers in China: comparative analysis from the 2014 Guangdong Migrant Workers Survey. Asia Pacific Journal of Human Resources. 2018;56(4):518-38.

[14] Keung Wong DF, Li CY, Song HX. Rural migrant workers in urban China: living a marginalised life. International Journal of Social Welfare. 2007;16(1):32-40.

[15] Noy I. The macroeconomic consequences of disasters. Journal of Development Economics. 2009;88(2):221-31.

[16] Blake D, Marlowe J, Johnston D. Get prepared: Discourse for the privileged? International Journal of Disaster Risk Reduction. 2017;25:283-8.

[17] Giddens A. The consequences of modernity. Cambridge, UK: Polity Press; 1991.

[18] Banham R. Emotion, vulnerability, ontology: operationalising 'ontological security' for qualitative environmental sociology. Environmental Sociology. 2020;6(2):1-11.

[19] Lan X, Yiran J, Nan C, Liuxia Z, Shuaiqin Z. Hometown is the most reassuring place: The impact of ontological security threat on preference of hometown brands. Acta Psychologica Sinica. 2020;52(04):513-27.

[20] Dupuis A, Thorns DC. Home, Home Ownership and the Search for Ontological Security. The Sociological Review. 1998;46(1):24-47.

[21] SKEY M. 'A sense of where you belong in the world': national belonging, ontological security and the status of 
the ethnic majority in England. Nations and Nationalism. 2010;16(4):715-33.

[22] Hawkins RL, Maurer K. 'You fix my community, you have fixed my life': the disruption and rebuilding of ontological security in New Orleans. Disasters. 2011;35(1):143-59.

[23] Carroll B, Morbey H, Balogh R, Araoz G. Flooded homes, broken bonds, the meaning of home, psychological processes and their impact on psychological health in a disaster. Health Place. 2009;15(2):540-7.

[24] Tapsell SM, Tunstall SM. "I wish I'd never heard of Banbury": The relationship between 'place' and the health impacts from flooding. Health Place. 2008;14(2):133-54.

[25] Padgett DK. There's no place like (a) home: Ontological security among persons with serious mental illness in the United States. Social Science \& Medicine. 2007; 64(9):1925-36.

[26] Phipps M, Ozanne JL. Routines Disrupted: Reestablishing Security through Practice Alignment. Journal of Consumer Research. 2017;44(2):361-80.

[27] Kirkman M, Keys D, Bodzak D, Turner A. 'I just wanted somewhere safe': Women who are homeless with their children. Journal of Sociology. 2015;51(3):722-36.

[28] Vaquera E, Aranda E, Sousa-Rodriguez I. Emotional Challenges of Undocumented Young Adults: Ontological Security, Emotional Capital, and Well-being. Social Problems. 2017;64(2):298-314.

[29] Haney TJ, Gray Scholz D. Flooding and the 'new normal': what is the role of gender in experiences of post-disaster ontological security? Disasters. 2020;44(2):262-84.

[30] Mullainathan S, Shafir E. Scarcity: why having too little means so much. New York: Times Books, Henry Holt and Company; 2013.

[31] Shah AK, Mullainathan S, Shafir E. Some Consequences of Having Too Little. Science. 2012;338(6107):682-5.

[32] Norris AH, Rao N, Huber-Krum S, Garver S, Chemey E, Norris Turner A. Scarcity mindset in reproductive health decision making: a qualitative study from rural Malawi. Culture, Health \& Sexuality. 2019;21(12):1333-48.

[33] Huijsmans I, Ma I, Micheli L, Civai C, Stallen M, Sanfey AG. A scarcity mindset alters neural processing underlying consumer decision making. Proceedings of the National Academy of Sciences - PNAS. 2019;116(24): 11699-704.

[34] Boyer TW. The development of risk-taking: A multiperspective review. Developmental Review. 2006;26(3): 291-345.

[35] Figner B, Weber EU. Who Takes Risks When and Why? Determinants of Risk Taking. Current Directions in Psychological Science. 2011;20(4):211-6.

[36] Gamba A, Gamba A, Manzoni E, Manzoni E, Stanca L, Stanca L. Social comparison and risk taking behavior. Theory and Decision. 2017;82(2):221-48.

[37] Simpson JA, Griskevicius V, Kuo SI, Sung S, Collins WA. Evolution, stress, and sensitive periods: the influence of unpredictability in early versus late childhood on sex and risky behavior. Developmental Psychology. 2012; 48(3):674-86.

[38] Ellis BJ, Figueredo AJ, Brumbach BH, Schlomer GL. Fundamental Dimensions of Environmental Risk: The Impact of Harsh versus Unpredictable Environments on the Evolution and Development of Life History Strategies. Human Nature. 2009;20(2):204-68.

[39] Griskevicius V, Ackerman JM, Cantú SM, Delton AW, Robertson TE, Simpson JA, et al. When the Economy Falters, Do People Spend or Save? Responses to Resource
Scarcity Depend on Childhood Environments. Psychological Science. 2013;24(2):197-205.

[40] Mishra S, Lalumière ML. You can't always get what you want: The motivational effect of need on risk-sensitive decision-making. Journal of Experimental Social Psychology. 2010;46(4):605-11.

[41] Gonzales J, Mishra S, Camp RD. For the Win: RiskSensitive Decision-Making in Teams. Journal of Behavioral Decision Making. 2017;30(2):462-72.

[42] Finucane ML, Gullion CM. Developing a Tool for Measuring the Decision-Making Competence of Older Adults. Psychology and Aging. 2010;25(2):271-88.

[43] Kahneman D, Frederick S. Frames and brains: elicitation and control of response tendencies. TRENDS COGN SCI. 2006;11(2):45-6.

[44] Sirota M, Juanchich M. Effect of response format on cognitive reflection: Validating a two- and four-option multiple choice question version of the Cognitive Reflection Test. Trends in Cognitive Sciences. 2018;50(6):2511-22.

[45] Maccheroni F, Marinacci M, Rustichini A. Social Decision Theory: Choosing within and between Groups. The Review of Economic Studies. 2012;79(4):1591-636.

[46] Festinger L. A Theory of Social Comparison Processes. Human Relations. 1954;7(2):117-40.

[47] Smith CE, Blake PR, Harris PL. I Should but I Won't: Why Young Children Endorse Norms of Fair Sharing but Do Not Follow Them. PLOS ONE. 2013;8(3):e59510.

[48] Wen L, Xue Z, Yu Z, Ruiwei Y. Fairness cognition-behavior gap in 48 year-old children: The role of social comparison. Acta Psychologica Sinica. 2017;49(12):1504-12.

[49] Mishra S, Hing LSS, Lalumière ML. Inequality and RiskTaking. Evolutionary Psychology. 2015;13(3):1505515827.

[50] Yunqiang S, Ruihang X, Cai X. Risk sensitivity theory: need to drive risk decision. Advances in Psychological Science. 2017;25(03):486-99.

[51] Mishra S, Barclay P, Lalumière ML. Competitive disadvantage facilitates risk taking. Evolution and Human Behavior. 2014;35(2):126-32.

[52] Payne BK, Brown-Iannuzzi JL, Hannay JW. Economic inequality increases risk taking. Proceedings of the National Academy of Sciences of the United States of America. 2017;114(18):4643-8.

[53] Weber EU, Blais AR, Betz NE. A domain-specific risk-attitude scale: measuring risk perceptions and risk behaviors. Journal of Behavioral Decision Making. 2002; 15(4):263-90.

[54] Blais A, Weber EU. A Domain-Specific Risk-Taking (DOSPERT) scale for adult populations. Judgment and Decision Making. 2006;1(1):33.

[55] Wang XTX, Zheng R, Xuan Y, Chen J, Li S. Not all risks are created equal: A twin study and meta-analyses of risk taking across seven domains. Journal of Experimental Psychology. General. 2016;145(11):1548-60.

[56] Tversky A, Kahneman D. Judgment under Uncertainty: Heuristics and Biases. Science. 1974;185(4157):1124-31.

[57] Holroyd CB, Coles MGH. The Neural Basis of Human Error Processing: Reinforcement Learning, Dopamine, and the Error-Related Negativity. Psychological Review. 2002;109(4):679-709.

[58] Williams CC, Saffer BY, McCulloch RB, Krigolson OE. The scarcity heuristic impacts reward processing within the medial-frontal cortex. NeuroReport. 2016;27(7):522-6.

[59] Frederick S. Cognitive Reflection and Decision Making. The Journal of Economic Perspectives. 2005;19(4): 25-42. 
[60] Zhang DC, Highhouse S, Nye CD. Development and validation of the General Risk Propensity Scale (GRiPS). Journal of Behavioral Decision Making. 2019;32(2):152-67.

[61] Roux C, Goldsmith K, Bonezzi A. On the Psychology of Scarcity: When Reminders of Resource Scarcity Promote Selfish (and Generous) Behavior. Journal of Consumer Research. 2015;42(4):615-31.

[62] Jingkun N, Haifeng D, Wei W, Xi L. The Impact of Perceived Justice on Migrant Workers' Collective Action—_Based on Moderating Effect of Equal Awareness. Journal of Public Management. 2016;13(03):89-99.

[63] Zhao X, Lynch JG, Chen Q, John DSAE. Reconsidering Baron and Kenny: Myths and Truths about Mediation Analysis. Journal of Consumer Research. 2010;37(2):197-206.
[64] Fischhoff B. Hindsight not equal to foresight: the effect of outcome knowledge on judgment under uncertainty. 1975. Quality \& Safety in Health Care. 2003;12(4):304.

[65] Bao Y, Zhou KZ, Su C. Face consciousness and risk aversion: Do they affect consumer decision-making? Psychology \& Marketing. 2003;20(8):733-55.

[66] Wong NY, Ahuvia AC. Personal taste and family face: Luxury consumption in Confucian and western societies. Psychology \& Marketing. 1998;15(5):423-41. 